\title{
In Situ Catalytic Pyrolysis of Low-Rank Coal for the Conversion of Heavy Oils into Light Oils
}

\author{
Muhammad Nadeem Amin, Yi Li, and Xingmei Lu \\ Beijing Key Laboratory of Ionic Liquids Clean Process, Key Laboratory of Green Process and Engineering, \\ State Key Laboratory of Multiphase Complex Systems, Institute of Process Engineering, Chinese Academy of Sciences, \\ Beijing 100190, China \\ Correspondence should be addressed to Yi Li; liyi@ipe.ac.cn
}

Received 18 August 2016; Accepted 27 September 2016; Published 22 January 2017

Academic Editor: Faheem K. Butt

Copyright (C) 2017 Muhammad Nadeem Amin et al. This is an open access article distributed under the Creative Commons Attribution License, which permits unrestricted use, distribution, and reproduction in any medium, provided the original work is properly cited.

\begin{abstract}
Lighter tars are largely useful in chemical industries but their quantity is quite little. Catalytic cracking is applied to improve the yield of light tars during pyrolysis. Consequently, in situ upgrading technique through a $\mathrm{MoS}_{2}$ catalyst has been explored in this research work. $\mathrm{MoS}_{2}$ catalyst is useful for the conversion of high energy cost into low energy cost. The variations in coal pyrolysis tar without and with catalyst were determined. Meanwhile, the obtained tar was analyzed using simulated distillation gas chromatograph and Elemental Analyzer. Consequently, the catalyst reduced the pitch contents and increased the fraction of light tar from 50 to 60 wt.\% in coal pyrolysis tar. $\mathrm{MoS}_{2}$ catalyst increased the liquid yield from 18 to 33 (wt.\%, db) and decreased gas yield from 27 to 12 (wt.\%, $\mathrm{db}$ ) compared to coal without catalyst. Moreover, it increased $\mathrm{H}$ content and hydrogen-to-carbon ratio by 7.9 and $3.3 \%$, respectively, and reduced the contents of nitrogen, sulphur, and oxygen elements by $8.1 \%, 15.2 \%$, and $23.9 \%$, respectively, in their produced tars compared to coal without catalyst.
\end{abstract}

\section{Introduction}

Coal is heterogeneously complex structure having organic and inorganic macromolecules. Low-rank coals have great importance in utilization but have some problems due to low efficiency and higher $\mathrm{CO}_{2}$ emissions compared to highrank coals. These coals are difficult for storage and transportation and are not suitable for direct combustion [15]. The utilization of a low-grade coal could be achieved through pyrolysis which converts the coal volatiles into high valuable fuels and fine chemicals. A coal tar in bulk quantity is produced during pyrolysis, but it contains high range of heavy organic components having boiling point greater than $360^{\circ} \mathrm{C}$ called pitch. The high boiling point range organic components are not easy to be treated since they can easily precipitate in the pipelines with dusts, so they will create problems during operation of downstream equipment like engines and turbines and block the pipelines in the industry. High valuable tar can be achieved to crack high range organic heavy components into desired components having boiling point less than $360^{\circ} \mathrm{C}$. However, the thermal cracking of tar generally occurs at high temperature through appropriate energy supply and reaction time which leads to decreasing the energy efficiency and tar yield. So, the catalytic coal pyrolysis is the most promising technique to upgrade the coal pyrolysis tar under moderate conditions and increase the energy efficiency of industrial equipment [6-21].

To improve the tar yield and fraction of light components in coal tar, catalytic coal pyrolysis experiments have been performed through mixing or without mixing of coal with catalysts in previous study [22-31]. Li et al. [25] were reported to improve aromatic components yield like BTEXN on zeolite catalysts. Liu et al. [26] studied improving the yield of tar over $\mathrm{Ni}-\mathrm{MgO}$ and obtained the higher tar yield, when the coal during pyrolysis was incorporated to $\mathrm{CO}_{2}$ for reforming methane. Jin et al. [27] studied improving the tar yield on zeolite catalyst (Mo-HZSM-5) for integrating the aromatization of methane during coal pyrolysis and obtained yield of coal tar about $21.5 \%$ at the pyrolysis temperature of $700^{\circ} \mathrm{C}$. Li et al. [28] investigated the long flame Huang Tu Miao 
TABLE 1: Results of Shengli raw coal.

\begin{tabular}{lcccccccc}
\hline & \multicolumn{2}{c}{ Proximate (air-dried base, wt.\%) } & \multicolumn{3}{c}{ Ultimate (dry-free base, wt.\%) } \\
M & A & Vol.Mat. & Fix.C. & C & H & N & S & $\mathrm{O}^{\text {b }}$ \\
\hline 15.0 & 4.2 & 32.04 & 48.76 & 74.55 & 4.38 & 1.03 & 0.35 & 19.69 \\
\hline
\end{tabular}

M: moisture; A: ash; Vol.Mat.: volatiles matter; Fix.C: fixed carbon.

${ }^{\mathrm{b}}$ Difference from calculation.

coal over different catalysts $(\mathrm{NaX}, \mathrm{CoO}, \mathrm{MoO}$, and $\mathrm{CoO}$ $\mathrm{MoO}$ ) and enriched $\mathrm{CO}, \mathrm{CH}_{4}$, and aromatic components formation with $\mathrm{NaX}$ zeolite catalyst. Ma et al. [29] studied five Chinese coals with mechanical mixing of catalyst and coals on catalytic hydropyrolysis to represent the increase in liquid yield with a small influence on BTX yield over $\mathrm{ZnCl}_{2}$ and $\mathrm{MoS}_{2}$ improved BTX and gases yield. Li et al. [30] explored the product analysis of impregnated lignite coal with sulphided molybdenum catalyst and exhibited increment in yield of tar up to about $63.9 \%$ as well as light aromatics such as BTX, phenol, cresol, and xylenol (PCX), and naphthalene also increased during the catalytic multistage hydropyrolysis (MHyPy) as compared to the traditional hydropyrolysis. The preceding studies for enhancing the coal pyrolysis tar are generally under hydrogen and pressure conditions [31,32], while their large observations have been dedicated to the differences of specific components like BTEXN.

In foregoing work, mechanical mixing and impregnation of $\mathrm{MoS}_{2}$ catalyst with lignite coals were applied on the basis of research aims during catalytic hydropyrolysis $[29,30]$. Thus, low-grade coal in this research's aim and $\mathrm{MoS}_{2}$ catalyst were used separately in a dual-stage reactor having two sections through atmospheric pressure for the enhancement of coal pyrolysis tar. Moreover, the catalytic effect of $\mathrm{MoS}_{2}$ on coal tar quality in terms of distilled temperature difference was investigated and also the behavior of catalytic upgrading in the conversion of heavy tar components was studied.

\section{Experimental Portion}

2.1. Synthesis of Raw Coal and Catalyst. Low-rank Shengli coal was grounded to the required size (20-40 mesh) for testing of experiments. Table 1 shows the results of raw Shengli coal. Raw coal was held for drying overnight at $120^{\circ} \mathrm{C}$ before each testing. A material $\mathrm{MoS}_{2}(\geq 98 \%)$ as a catalyst supplied by Sinopharm Chemical Reagent Co., Ltd., was selected and amount of $\mathrm{MoS}_{2}$ catalyst $(2.5 \mathrm{~g}$ ) was used in each experiment. The powder $\mathrm{MoS}_{2}$ material was heated at $120^{\circ} \mathrm{C}$ and then calcined at $500^{\circ} \mathrm{C}$ within $4 \mathrm{~h}$. It was pelletized with machine (769YB-24B) at $10 \mathrm{MPa}$ pressure and then sieved to particle size of 20-40 meshes.

2.2. Testing Method. The testing section consisted of gas supply, a dual-stage fixed bed reactor, electric ring furnace, and tar and gas collection system as shown in Figure 1 as reported in our last research [33]. It was prepared through glass tube containing three parts including upper section, lower section, and a cover. The upper section containing a porous sintering quartz plate was used for the coal pyrolysis having $30 \mathrm{~mm}$ inner diameter and $200 \mathrm{~mm}$ length. The lower section was adopted for primary products during pyrolysis having $34 \mathrm{~mm}$ inner diameter and $550 \mathrm{~mm}$ length. Both parts were externally heated by an electric ring furnace. Two K-type thermocouples were kept inside the reactor for temperatures such as pyrolysis and cracking.

High purity $\mathrm{N}_{2}$ carrier gas (Beiwen, Beijing, China, 99.99\%) was controlled with a mass flow meter. It gave pyrolysis initial reaction in the dual-bed reactor. A $5 \mathrm{~g}$ coal was kept in the upper part of the pyrolysis and $2.5 \mathrm{~g}$ catalyst was kept in lower part of the catalytic upgrading of coal. The pyrolysis products from the upper section were transformed and go through the catalyst bed in lower part. Finally, obtained product was passed through condenser; it was cleaned with acetone thoroughly to get coal pyrolysis tar. Noncondensable pyrolysis gases were dewatered through calcium chloride block and received in gas bags. All pipelines were cleaned using acetone and then the liquid was obtained. The obtained liquid (acetone plus water) including tar was first dehydrated with $\mathrm{MgSO}_{4}$. It was kept on filter paper for filtration and the acetone was removed at $30^{\circ} \mathrm{C}$ in a rotary machine to get coal pyrolysis tar.

The experiments represented that reaction can finish within about 40 min during pyrolysis. The testing methods for coal with and without catalyst were as follows. A $5 \mathrm{~g}$ coal was pyrolyzed without catalyst in the upper part through electric furnace. It was performed for heating the coal through a temperature controller with $100^{\circ} \mathrm{C}$ per minute to $600^{\circ} \mathrm{C}$ temperature. Coal $(5 \mathrm{~g})$ was pyrolyzed and catalyst $(2.5 \mathrm{~g})$ was also put in lower part during upgrading of coal pyrolysis tar. Both parts were heated with a rate of $100^{\circ} \mathrm{C}$ per minute at $50 \mathrm{~mL}$ per min of gas flow from ambient to $600^{\circ} \mathrm{C}$ temperature. Both pyrolysis and cracking temperatures were kept within $30 \mathrm{~min}$ at $600^{\circ} \mathrm{C}$. All performed tests were repeated three times and average was calculated as the final reading.

2.3. Coal Derived Products and Catalyst Analysis. Noncondensable and hydrocarbon gases were measured through a gas chromatograph as described in our last work [33]. The coal pyrolysis tar having aromatic and hydrocarbons was measured through analysis equipment as reported in our last study [33]. The boiling point range less than $360^{\circ} \mathrm{C}$ refers to the light tar and heavy tar having more than $360^{\circ} \mathrm{C}$.

The catalyst characterization was analyzed through X-ray pattern machine and micropore analyzer as described in our last article [33]. The catalyst morphology was seen through scanning electron microscopy (SEM) with a JOEL machine (JSM-6700F) and transmission electron microscopy (TEM) was adopted to measure the catalyst with a JOEL (JEM2100F). 


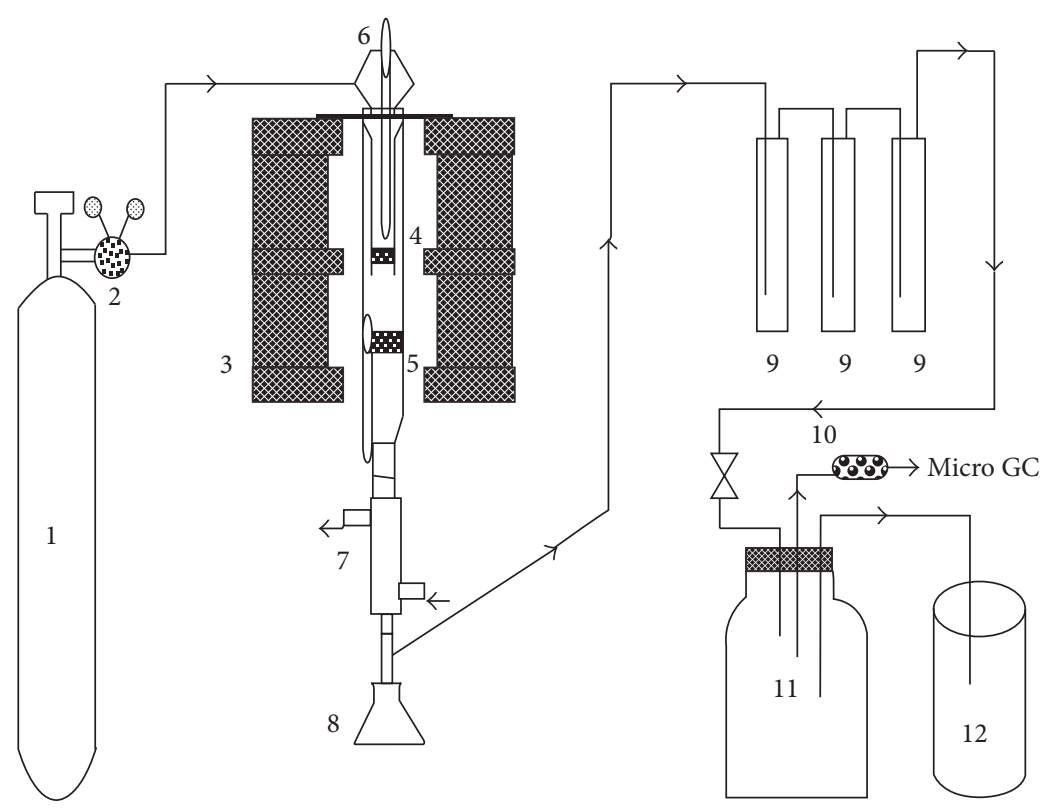

FIgURE 1: A schematic figure of the experimental apparatus. (1) nitrogen cylinder, (2) flow controller, (3) electric ring furnace, (4) coal layer, (5) catalyst layer, (6) thermocouple, (7) condenser, (8) conical flask, (9) acetone traps, (10) silica gel, (11) gas collector, and (12) measuring cylinder.

Coal tar yield $\left(Y_{\text {tar }}\right)$, lighter tar fraction $\left(f_{\text {light }}\right)$, lighter tar yield $\left(Y_{\text {light tar }}\right)$, noncondensed pyrolysis gas yield $Y_{i}$, gas yield $Y_{\text {gas }}$, char yield $Y_{\text {char }}$, and liquid yield $Y_{\text {liquid }}$ were calculated using (1) to (7) for the distribution of pyrolysis products.

Tar yield is given as follows:

$$
Y_{\mathrm{tar}}=\frac{W_{\mathrm{tar}}}{W} .
$$

Light tar fraction is given as follows:

$$
f_{\text {light }}=\frac{W_{\text {light tar }}}{W_{\text {tar }}}
$$

Light tar yield is given as follows:

$$
Y_{\text {light tar }}=Y_{\text {tar }} \times f_{\text {light }} .
$$

Pyrolysis gas yield is given as follows:

$$
Y_{i}=\frac{W_{i}}{W}
$$

Gas yield is given as follows:

$$
Y_{\text {gas }}=\frac{W_{\text {gas }}}{W} \text {. }
$$

Char yield is given as follows:

$$
Y_{\text {char }}=\frac{W_{\text {char }}}{W} .
$$

Liquid yield is given as follows:

$$
Y_{\text {liquid }}=1-Y_{\text {gas }}-Y_{\text {char }} \text {. }
$$

$W, W_{\text {tar }}, W_{\text {light tar }}, W_{i}, W_{\text {gas }}$, and $W_{\text {char }}$ represent the masses of raw coal, tar, light tar, noncondensed pyrolysis gas components, pyrolysis gas, and char in grams, respectively, and $i$ in $Y_{i}$ shows the pyrolysis components of gas.

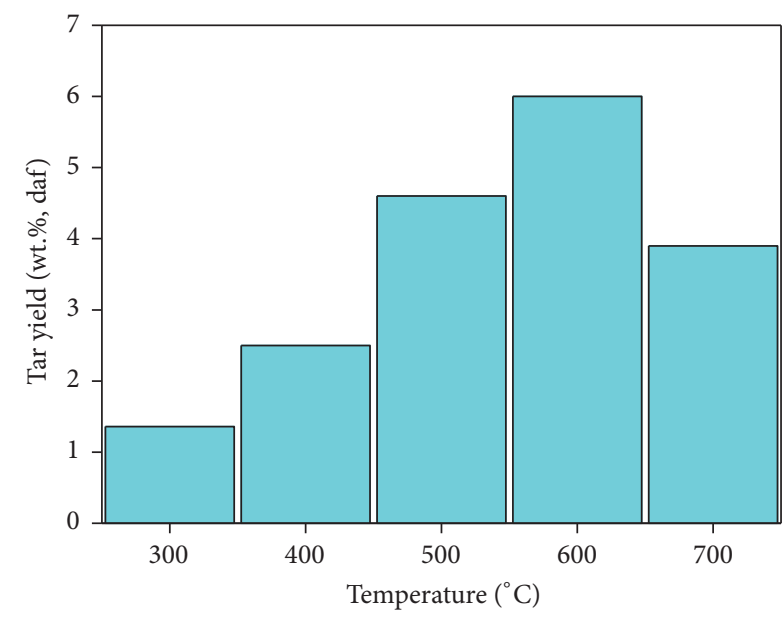

FIGURE 2: Tar yield based on temperatures without catalyst.

\section{Results and Discussion}

3.1. Temperature Influence on Coal without Catalyst. Coal having tar yield from 300 to $700^{\circ} \mathrm{C}$ is shown in Figure 2. It determined the suitable temperature that led to the maximum tar yield. More volatile matters were released at more than $600^{\circ} \mathrm{C}$ temperature and moved towards large cracking reactions to reduce coal tar yield during pyrolysis. Therefore, the temperature $600^{\circ} \mathrm{C}$ was selected. The product yields including gas, liquid, and char during coal pyrolysis without catalyst are depicted as in Figure 3. It can be stated that increase in gas yield occurred with the temperature from 300 to $700^{\circ} \mathrm{C}$. The gas yield was increased which might be due to evolution of micro compounds due to the secondary tar reactions 


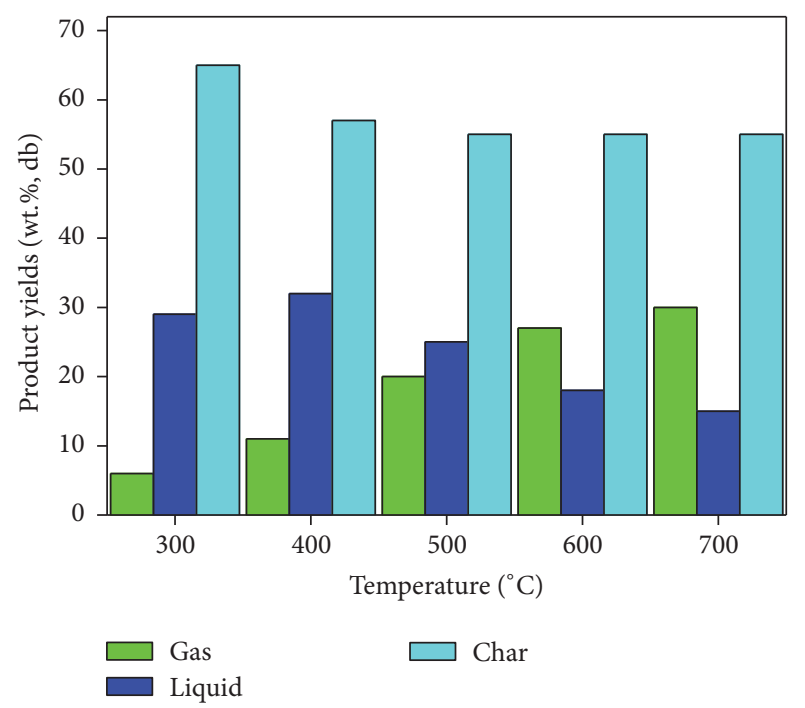

Figure 3: Pyrolysis product yields based on temperatures without catalyst.

and large amount of volatiles was achieved at $600^{\circ} \mathrm{C}$ during pyrolysis. It was also observed that liquid yield increased from 300 to $400^{\circ} \mathrm{C}$ and then decreased. The reduction in liquid yield from 500 to $700^{\circ} \mathrm{C}$ indicates high reaction rates during decomposition. The expression of increase and reduction in liquid yield with temperature was reported in literature $[34,35]$. The declining in char yield occurred from 300 to $500^{\circ} \mathrm{C}$ and then became stable above $500^{\circ} \mathrm{C}$ temperature. The stability of char yield above $500^{\circ} \mathrm{C}$ showed the complete burning of coal during pyrolysis. The temperature more than $600^{\circ} \mathrm{C}$ is attributed to the increment of gas yield and reduction in coal tar yield.

3.2. Catalyst's Influence on Pyrolysis Product Yields. The catalyst having influence on yield of pyrolysis products during coal pyrolysis is described in Figure 4. It can be noted that the increment in liquid yield from 18 to 33 (wt.\%, db) occurred due to catalytic effect during coal pyrolysis. The liquid yield increment might be due to high condensation reaction during catalytic coal pyrolysis, while gas yield decreased from 27 to $12(\mathrm{wt} . \%, \mathrm{db})$ after catalysis and char yield $(55 \mathrm{wt} . \%, \mathrm{db})$ remained constant before and after catalyst. These results showed that decrease in gas yield might be due to the catalytic effect on the released volatiles during coal pyrolysis. The liquid yield increment and gas yield reduction with the catalyst were studied in literature [31].

3.3. Gas Composition without and with Catalyst during Coal Pyrolysis. Pyrolysis gas components and hydrocarbon gases $\left(\mathrm{C}_{m} \mathrm{H}_{n}\right)$ without and with catalyst are shown in Figure 5. It can be thought that gas components yield declined after catalysis. The pyrolysis of low-rank coal produces rich oxide of carbon due to large content of oxygen in raw material. The pyrolysis gases can provide energy requirement for plant during pyrolysis due to high content of carbon oxides [36]. The yields of gas components $\left(\mathrm{H}_{2}, \mathrm{CH}_{4}\right.$, and $\left.\mathrm{CO}\right)$ generated

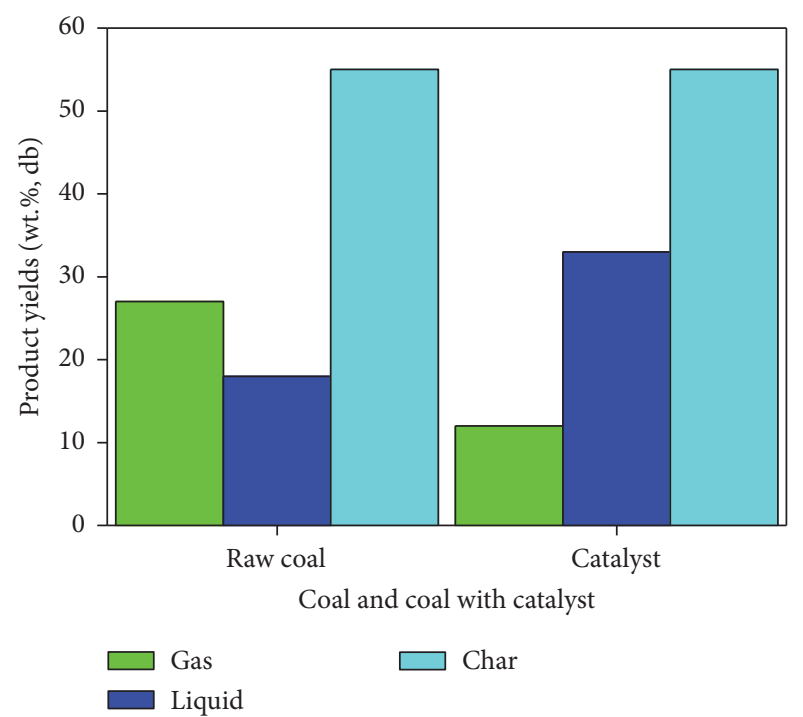

FIgURE 4: Pyrolysis product yields without and with catalyst.

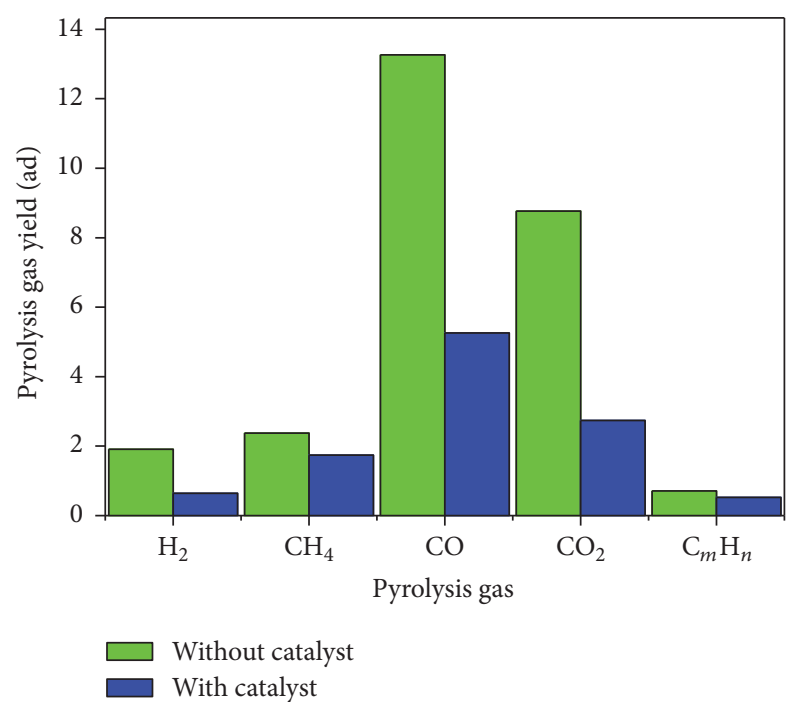

FIgURE 5: Gas components without and with catalyst.

through the condensation reactions, whereas the yield of $\mathrm{CO}_{2}$ was produced due to the cracking of carboxyl group from coal during pyrolysis [37]. Thus, carbon oxide gases also decreased after catalysis. Therefore, the catalyst might be catalyzing the forward and reverse water gas reactions, which are attributed to declining gas yields.

3.4. Tar Characterization. Tar fraction as a function of simulated distillation temperature without and with catalyst is shown in Figure 6. It is noted that initial and final temperatures of tar decreased after catalysis which indicated that tar evaporated rapidly. These results showed that the amount of light weight tars was higher than that without catalyst. The composition of tar before and after catalyst during pyrolysis is shown in Figure 7. The light weight tars fraction increased after catalysis; meanwhile the variations 
TABLE 2: Analysis of produced coal pyrolysis tars before and after reaction.

\begin{tabular}{|c|c|c|c|c|c|c|}
\hline \multirow[b]{2}{*}{ Catalyst } & \multicolumn{6}{|c|}{ Elemental analysis of coal pyrolysis tar (wt.\%) } \\
\hline & $\mathrm{C}$ & $\mathrm{H}$ & $\mathrm{N}$ & $S$ & $\mathrm{O}^{*}$ & $\begin{array}{c}\mathrm{H} / \mathrm{C} \\
\text { (ratio of moles) }\end{array}$ \\
\hline Without & 68.92 & 10.56 & 5.58 & 1.12 & 13.82 & 1.84 \\
\hline $\mathrm{MoS}_{2}$ & 72.0 & 11.40 & 5.13 & 0.95 & 10.52 & 1.90 \\
\hline
\end{tabular}

*By difference.

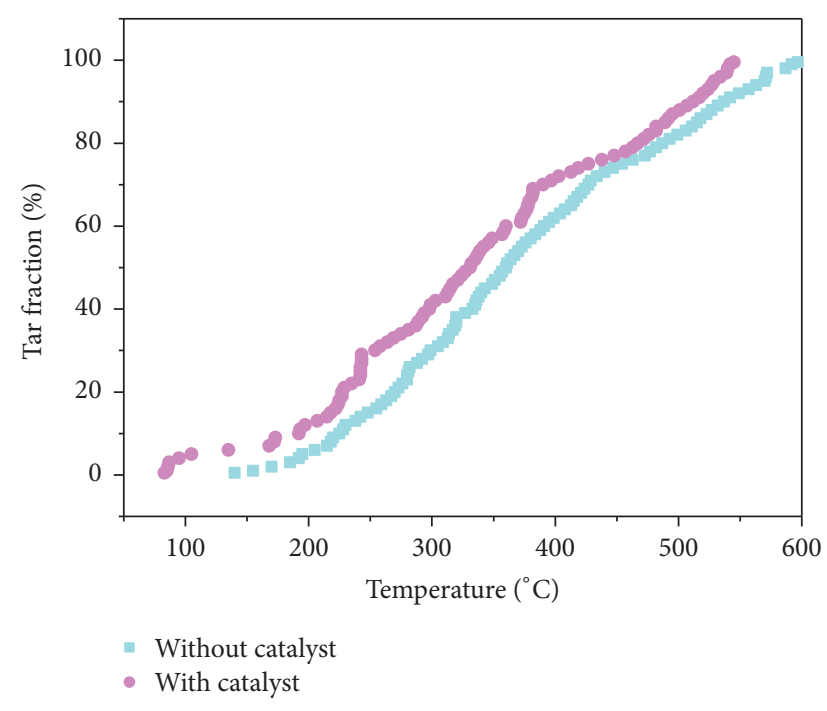

FIgURE 6: Tar fraction as a function of simulated distillation temperature without and with catalyst.

of wash and anthracene oils fractions were small. The pitch was also decreased after catalysis. For all compared data, the pyrolysis temperature in the upper layer was $600^{\circ} \mathrm{C}$, the adopted catalyst was $50 \mathrm{wt} . \%$ of the pyrolyzed coal, and the cracking temperature was $600^{\circ} \mathrm{C}$. Moreover, it is clear from Figures 5 and 6 that the catalyst had ability to produce more light weight tars during pyrolysis.

The tar yield, light tar fraction, and yield are represented in Figure 8. In this case, the fraction of light tar is the sum of all oil components in Figure 7 except pitch. Moreover, it can be seen that the light tar fraction increased from 50 to $60 \mathrm{wt} . \%$ for the secondary upgrading over $\mathrm{MoS}_{2}$ catalyst. The results showed that the secondary upgrading had greatly enhanced the overall tar quality, so that the downstream treatment could become more efficient and easier. In comparison to the coal pyrolysis without catalyst, the light tar yield with the catalyst increased significantly. It can be considered from light tar yield and fraction that $\mathrm{MoS}_{2}$ catalyst might have the best upgrading effect. The elemental analysis data of tar before and after catalyst is shown in Table 2. The coal pyrolysis with catalyst increased hydrogen-to-carbon ratio and also reduced nitrogen, sulphur, and oxygen elements in coal pyrolysis tar. After the catalysis, tar yield is declined, while hydrogen and hydrogen-to-carbon ratio are increased as 7.9 and 3.3\%, accordingly. Overall, $\mathrm{MoS}_{2}$ catalyst was highly efficient in producing lighter coal pyrolysis tar fraction, upgrading the

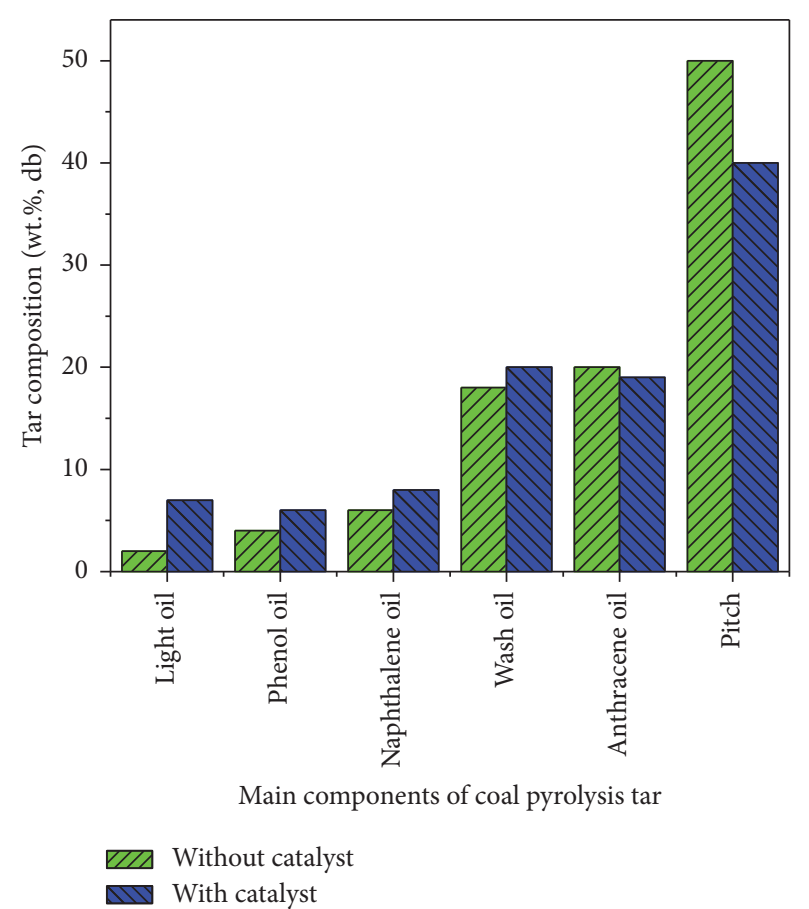

FIGURE 7: Tar composition of coal without and with catalyst.

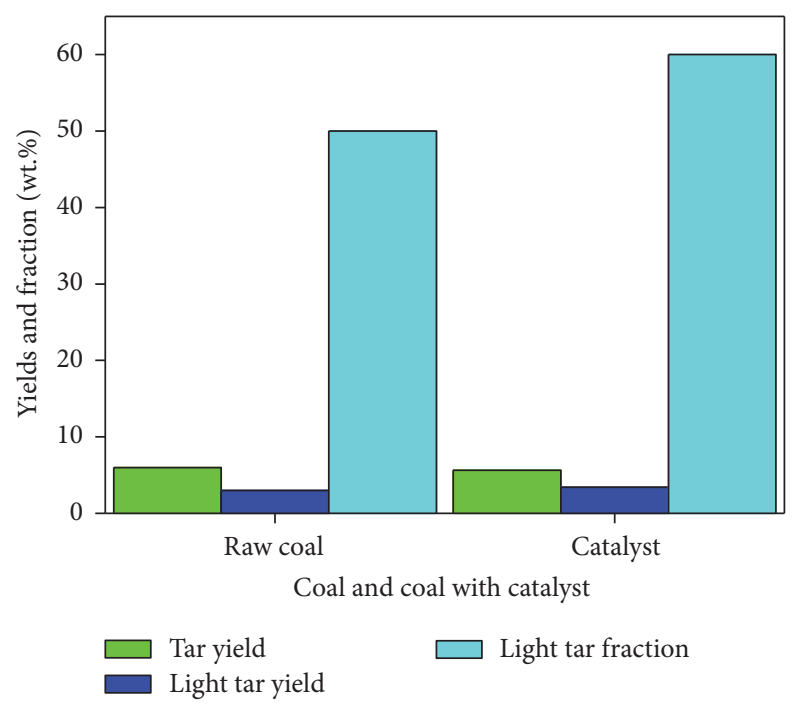

FIGURE 8: Yields and fraction of coal pyrolysis tar without and with catalyst. 


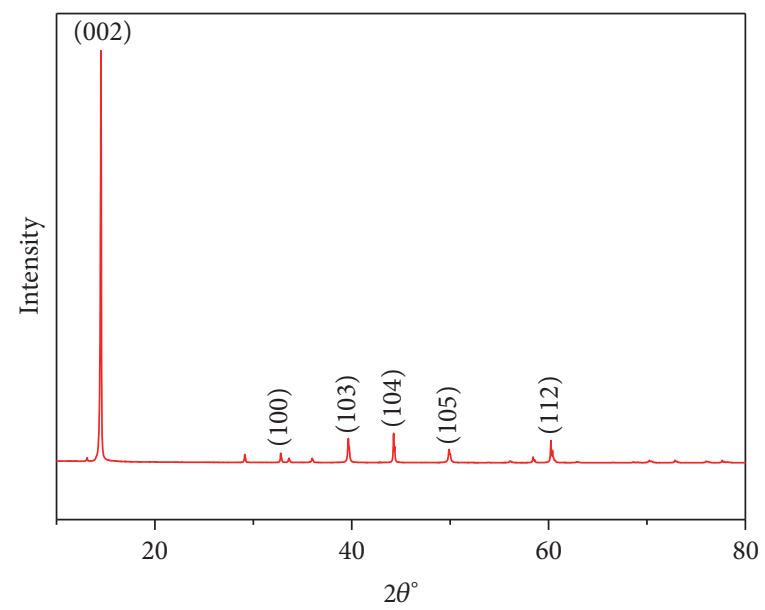

FIGURE 9: XRD pattern of $\mathrm{MoS}_{2}$ catalyst.

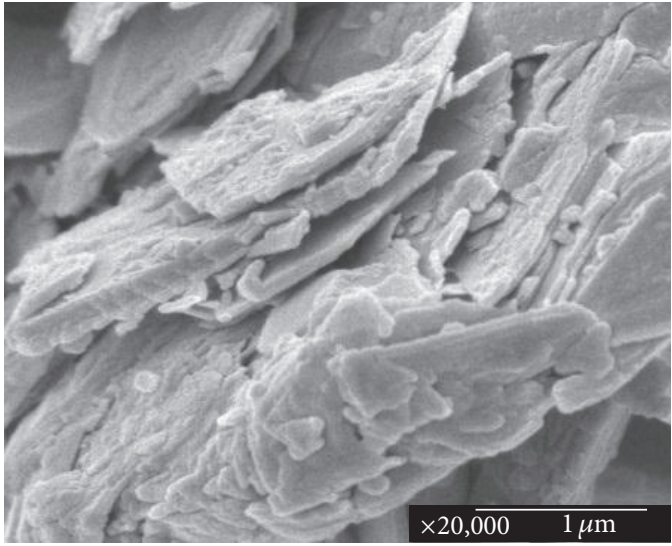

(a)

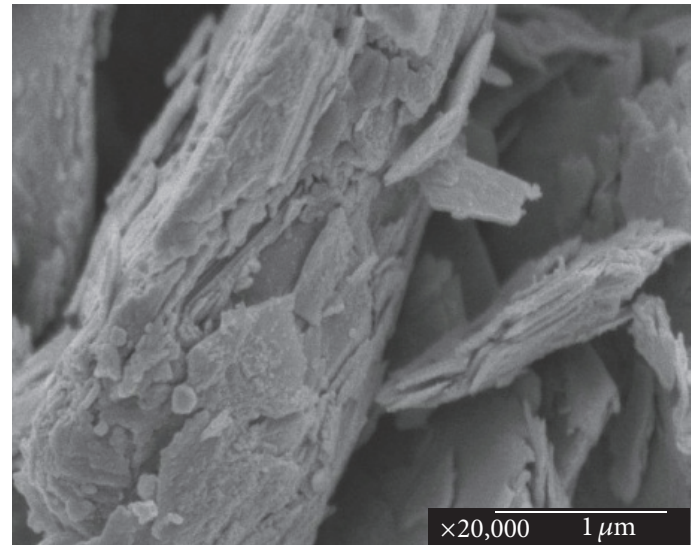

(b)

FIgURE 10: SEM diagrams of fresh $\mathrm{MoS}_{2}$ catalysts (a) and spent $\mathrm{MoS}_{2}$ catalyst (b).

coal tar products, and reducing the pitch contents in coal pyrolysis tar.

3.5. Catalyst Characterization. The XRD pattern of $\mathrm{MoS}_{2}$ catalyst is shown in Figure 9. A detailed view of diffraction peaks of the catalyst showed the formation of single-phase molybdenum sulfide $\left(\mathrm{MoS}_{2}\right)$ hexagonal structure as indicated by the index at $14.4^{\circ}, 32.7^{\circ}, 39.6^{\circ}, 44.3^{\circ}, 49.8^{\circ}$, and $60.4^{\circ}$ corresponding to the (002), (100), (103), (104), (105), and (112) crystal planes, respectively. The entire XRD diffraction pattern was attributed to exhibit pure $\mathrm{MoS}_{2}$ hexagonal form, which had well adjustment to the values as shown (JCPDS 65-1951). XRD pattern represented no other peaks, exhibiting pure form of $\mathrm{MoS}_{2}$ material. The strong and clear diffraction peaks showed that $\mathrm{MoS}_{2}$ material is highly crystalline. The highest intensity peak in the diffraction peaks shows high crystal formation.

The porosity of fresh and spent catalysts was calculated from nitrogen adsorption/desorption isotherms. The BET surface areas of the fresh and spent catalysts are 3 and $5 \mathrm{~m}^{2} \mathrm{~g}^{-1}$, respectively, and there was no significant difference between fresh and spent catalysts. The volume of pore in spent catalyst increased from 0.015 to $0.025 \mathrm{~cm}^{3} / \mathrm{g}$, while pore diameter was reduced from 23.65 to $16.66 \mathrm{~nm}$. It is realized that BET surface area and volume of pore increment might be attributed to the breakdown of pore which was suffered from high volatiles during pyrolysis and the cracking of coal pyrolysis tar.

The surface structure of fresh and spent catalysts with high magnification is shown in Figures 10(a) and 10(b). From Figures 10 (a) and 10(b), it can be seen that both catalysts were composed of $\mathrm{MoS}_{2}$ platelets. Figure 10(a) shows $\mathrm{MoS}_{2}$ crystals in the form of platelets. After the reaction, the $\mathrm{MoS}_{2}$ platelets formed a large lump which might be due to high temperature and upgrading the coal pyrolysis tar during pyrolysis. TEM diagrams of both catalysts (fresh and spent) are shown in Figures 11(a) and 11(b), respectively. From Figure 11(a), it is noted that the catalyst had nanoscale layer on its structure. The nanoscale accumulated phenomenon reduced the edge surface of the catalyst. It showed that sulphur atoms had strong molybdenum adsorption on the surface of the edges, while molybdenum had strongly adsorbed 


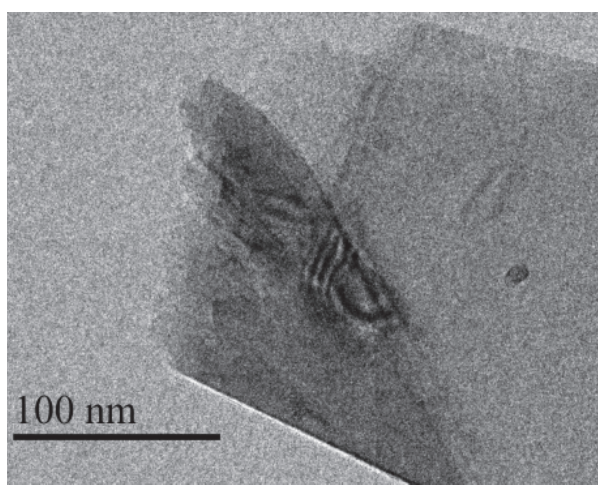

(a)

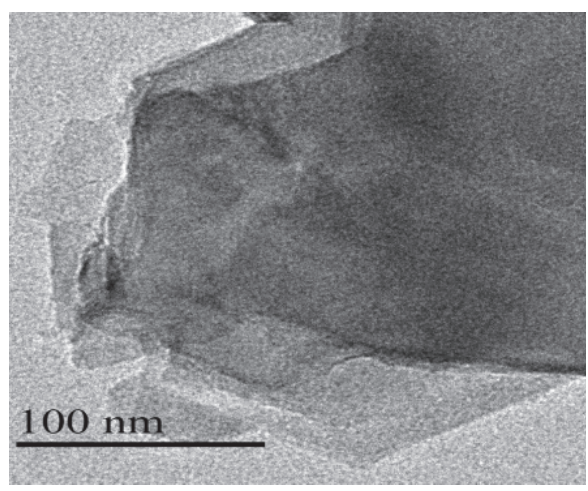

(b)

Figure 11: TEM diagrams of fresh $\mathrm{MoS}_{2}$ catalysts (a) and spent $\mathrm{MoS}_{2}$ catalyst (b).

sulphur atoms. After the reaction, the edges on the surface of the catalyst reduced and changed into small nanolayers. The formation of small nanolayers after the reaction might be due to high temperature and decomposition of the coal pyrolysis tar during catalytic coal pyrolysis. Moreover, TEM showed highly crystalline material; its size was around $100 \mathrm{~nm}$.

\section{Conclusions}

It was testified that $\mathrm{MoS}_{2}$ catalyst was able to increase liquid product yield and produced the highest liquid yield. Moreover, it is found that the catalyst decreased the pitch in the tar and showed the increment in the lighter weight tars fraction. Therefore, the catalyst was also active for the increment in hydrogen-to-carbon ratio and reduction in nitrogen, sulphur, and oxygen elements in coal pyrolysis tar. The catalyst in this study was more effective to upgrade the coal pyrolysis tar to decompose the coal catalytically, although $\mathrm{MoS}_{2}$ catalyst can promote the energy efficiency during the operation of industrial equipment.

\section{Competing Interests}

The authors declare that they have no competing interests.

\section{Acknowledgments}

In this research study, authors acknowledge gratefully the funding support of Beijing Natural Science Foundation (no. 3142020), Strategic Priority Research Program of CAS (no. XDA07010300), CAS Province Cooperation Program (no. 2014JZ0012), and National Major Instrumentation Development (no. 2011YQ12003907).

\section{References}

[1] N. Wang, J. Yu, A. Tahmasebi et al., "Experimental study on microwave pyrolysis of an Indonesian low-rank coal," Energy \& Fuels, vol. 28, no. 1, pp. 254-263, 2014.

[2] J. Yu, A. Tahmasebi, Y. Han, F. Yin, and X. Li, "A review on water in low rank coals: the existence, interaction with coal structure and effects on coal utilization," Fuel Processing Technology, vol. 106, pp. 9-20, 2013.

[3] A. Tahmasebi, J. Yu, Y. Han, F. Yin, S. Bhattacharya, and D. Stokie, "Study of chemical structure changes of chinese lignite upon drying in superheated steam, microwave, and hot air," Energy and Fuels, vol. 26, no. 6, pp. 3651-3660, 2012.

[4] M. Karthikeyan, W. Zhonghua, and A. S. Mujumdar, "LowRank coal drying technologies-current status and new developments," Drying Technology, vol. 27, no. 3, pp. 403-415, 2009.

[5] C. Bergins, S. Berger, and K. Strauß, "Dewatering of fossil fuels and suspensions of ultrafine particles by mechanical/thermal dewatering," Chemical Engineering and Technology, vol. 22, no. 11, pp. 923-927, 1999.

[6] J. Han, X. Wang, J. Yue, S. Gao, and G. Xu, "Catalytic upgrading of coal pyrolysis tar over char-based catalysts," Fuel Processing Technology, vol. 122, pp. 98-106, 2014.

[7] X. Qu, P. Liang, Z. Wang et al., "Pilot development of polygeneration process of circulating fluidized bed combustion combined with coal pyrolysis," Chemical Engineering \& Technology, vol. 34, no. 1, pp. 61-68, 2011.

[8] J. Wang, X. Lu, J. Yao, W. Lin, and L. Cui, "Experimental study of coal topping process in a downer reactor," Industrial and Engineering Chemistry Research, vol. 44, no. 3, pp. 463-470, 2005.

[9] T. Kimura, T. Miyazawa, J. Nishikawa et al., "Development of Ni catalysts for tar removal by steam gasification of biomass," Applied Catalysis B: Environmental, vol. 68, no. 3-4, pp. 160-170, 2006.

[10] S. J. Juutilainen, P. A. Simell, and A. O. I. Krause, "Zirconia: selective oxidation catalyst for removal of tar and ammonia from biomass gasification gas," Applied Catalysis B: Environmental, vol. 62, no. 1-2, pp. 86-92, 2006.

[11] P. Liang, Z. Wang, and J. Bi, "Process characteristics investigation of simulated circulating fluidized bed combustion combined with coal pyrolysis," Fuel Processing Technology, vol. 88, no. 1, pp. 23-28, 2007.

[12] C. Li and K. Suzuki, "Resources, properties and utilization of tar," Resources, Conservation and Recycling, vol. 54, no. 11, pp. 905-915, 2010.

[13] L. Li, K. Morishita, H. Mogi, K. Yamasaki, and T. Takarada, "Low-temperature gasification of a woody biomass under a nickel-loaded brown coal char," Fuel Processing Technology, vol. 91, no. 8, pp. 889-894, 2010. 
[14] L. Devi, K. J. Ptasinski, and F. J. J. G. Janssen, "A review of the primary measures for tar elimination in biomass gasification processes," Biomass and Bioenergy, vol. 24, no. 2, pp. 125-140, 2002.

[15] J. Han and H. Kim, "The reduction and control technology of tar during biomass gasification/pyrolysis: an overview," Renewable and Sustainable Energy Reviews, vol. 12, no. 2, pp. 397-416, 2008.

[16] A. V. Bridgwater, "The technical and economic feasibility of biomass gasification for power generation," Fuel, vol. 74, no. 5, pp. 631-653, 1995.

[17] D. Velegol, M. Gautam, and A. Shamsi, "Catalytic cracking of a coal tar in a fluid bed reactor," Powder Technology, vol. 93, no. 2, pp. 93-100, 1997.

[18] T. Kan, X. Sun, H. Wang, C. Li, and U. Muhammad, "Production of gasoline and diesel from coal tar via its catalytic hydrogenation in serial fixed beds," Energy \& Fuels, vol. 26, no. 6, pp. 36043611, 2012.

[19] T. Kan, H. Wang, H. He, C. Li, and S. Zhang, "Experimental study on two-stage catalytic hydroprocessing of middletemperature coal tar to clean liquid fuels," Fuel, vol. 90, no. 11, pp. 3404-3409, 2011.

[20] H. Wang, F. Dai, Z. Li, and C. Li, "Upgrading shale oil distillation to clean fuel by coupled hydrogenation and ring opening reaction of aromatics on $\mathrm{W}-\mathrm{Ni} / \gamma-\mathrm{Al}_{2} \mathrm{O}_{3}$ catalyst," Energy and Fuels, vol. 29, no. 8, pp. 4902-4910, 2015.

[21] H.-Y. Wang, T.-T. Jiao, Z.-X. Li, C.-S. Li, S.-J. Zhang, and J.-L. Zhang, "Study on palm oil hydrogenation for clean fuel over Ni-Mo-W/ $\gamma-\mathrm{Al}_{2} \mathrm{O}_{3}-\mathrm{ZSM}-5$ catalyst," Fuel Processing Technology, vol. 139, pp. 91-99, 2014.

[22] J. Shao, R. Yan, H. Chen, H. Yang, and D. H. Lee, "Catalytic effect of metal oxides on pyrolysis of sewage sludge," Fuel Processing Technology, vol. 91, no. 9, pp. 1113-1118, 2010.

[23] P. Wang, L. Jin, J. Liu, S. Zhu, and H. Hu, "Analysis of coal tar derived from pyrolysis at different atmospheres," Fuel, vol. 104, pp. 14-21, 2013.

[24] L. Yan, X. Kong, R. Zhao, F. Li, and K. Xie, "Catalytic upgrading of gaseous tars over zeolite catalysts during coal pyrolysis," Fuel Processing Technology, vol. 138, pp. 424-429, 2015.

[25] G. Li, L. Yan, R. Zhao, and F. Li, "Improving aromatic hydrocarbons yield from coal pyrolysis volatile products over HZSM-5 and Mo-modified HZSM-5," Fuel, vol. 130, pp. 154-159, 2014.

[26] J. Liu, H. Hu, L. Jin, P. Wang, and S. Zhu, "Integrated coal pyrolysis with $\mathrm{CO} 2$ reforming of methane over $\mathrm{Ni} / \mathrm{MgO}$ catalyst for improving tar yield," Fuel Processing Technology, vol. 91, no. 4, pp. 419-423, 2010.

[27] L. Jin, X. Zhou, X. He, and H. Hu, "Integrated coal pyrolysis with methane aromatization over Mo/HZSM-5 for improving tar yield," Fuel, vol. 114, pp. 187-190, 2013.

[28] S. Li, J. Chen, T. Hao et al., "Pyrolysis of Huang Tu Miao coal over faujasite zeolite and supported transition metal catalysts," Journal of Analytical and Applied Pyrolysis, vol. 102, pp. 161-169, 2013.

[29] Z. Ma, X. Ma, J. Luo, L. Xu, and F. Yang, "Catalytic hydropyrolysis of five Chinese coals," Energy and Fuels, vol. 26, no. 1, pp. 511-517, 2012.

[30] W. Li, N. Wang, and B. Li, "Product analysis of catalytic multistage hydropyrolysis of lignite," Fuel, vol. 82, no. 5, pp. 569-573, 2003.

[31] X. Zou, J. Yao, X. Yang, W. Song, and W. Lin, "Catalytic effects of metal chlorides on the pyrolysis of lignite," Energy \& Fuels, vol. 21, no. 2, pp. 619-624, 2007.
[32] W. Li, N. Wang, and B. Li, "Process analysis of catalytic multistage hydropyrolysis of lignite," Fuel, vol. 81, no. 11-12, pp. 14911497, 2002.

[33] M. N. Amin, Y. Li, R. Razzaq, X. Lu, C. Li, and S. Zhang, "Pyrolysis of low rank coal by nickel based zeolite catalysts in the two-staged bed reactor," Journal of Analytical and Applied Pyrolysis, vol. 118, pp. 54-62, 2016.

[34] D. I. Cliff, K. R. Doolan, J. C. Mackie, and R. J. Tyler, "Products from rapid heating of a brown coal in the temperature range 400-2300 •C," Fuel, vol. 63, no. 3, pp. 394-400, 1984.

[35] R. J. Tyler, "Flash pyrolysis of coals. 1. Devolatilization of a Victorian brown coal in a small fluidized-bed reactor," Fuel, vol. 58, no. 9, pp. 680-686, 1979.

[36] G. Duman, M. Pala, S. Ucar, and J. Yanik, “Two-step pyrolysis of safflower oil cake," Journal of Analytical and Applied Pyrolysis, vol. 103, pp. 352-361, 2013.

[37] Z. Tingyu, Z. Shouyu, H. Jiejie, and W. Yang, "Effect of calcium oxide on pyrolysis of coal in a fluidized bed," Fuel Processing Technology, vol. 64, no. 1, pp. 271-284, 2000. 

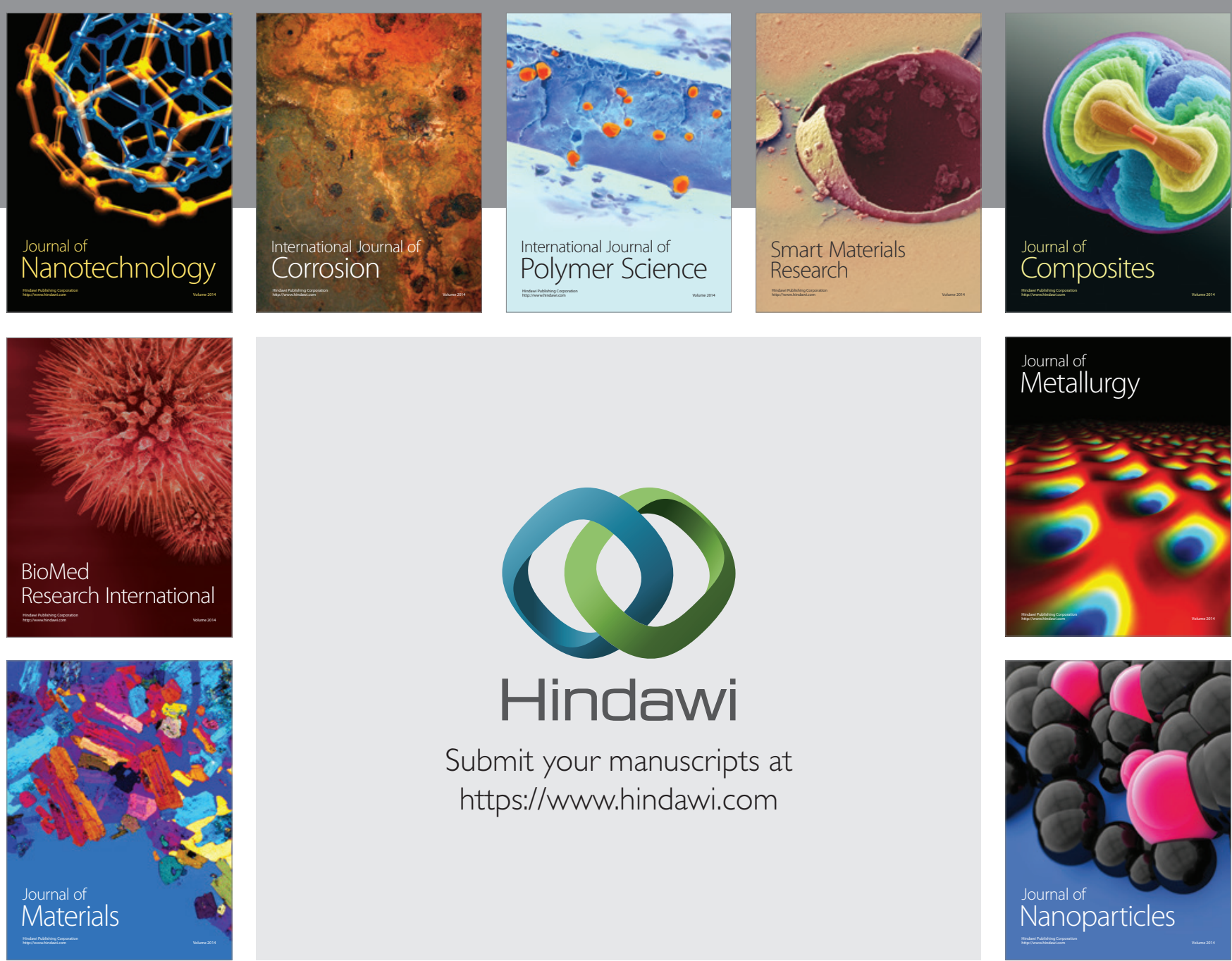

\section{Hindawi}

Submit your manuscripts at

https://www.hindawi.com

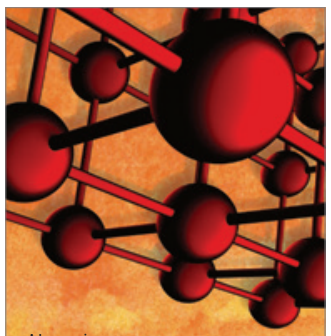

Materials Science and Engineering
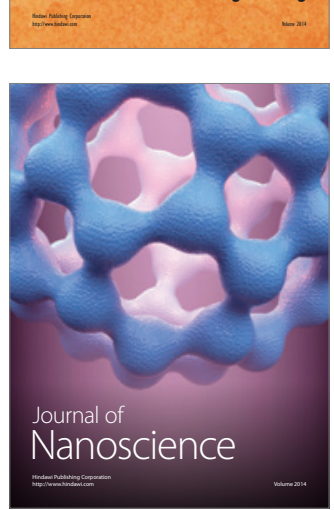
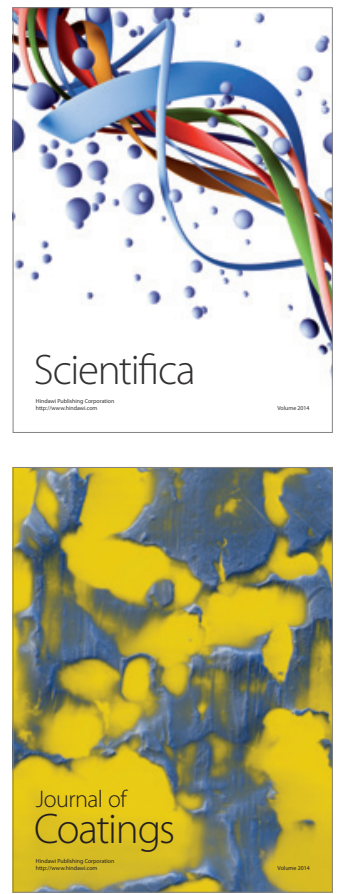
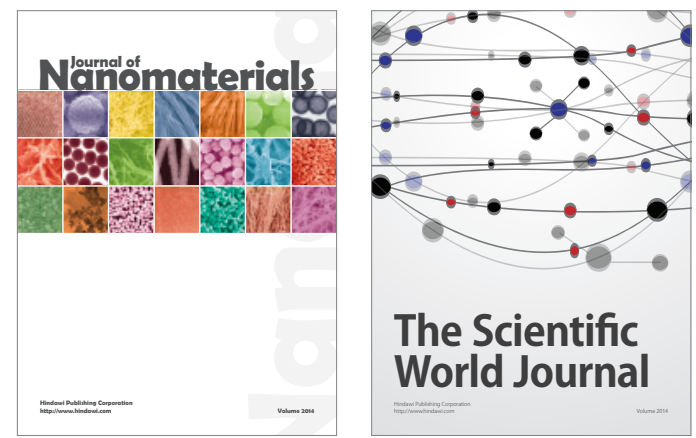

The Scientific World Journal
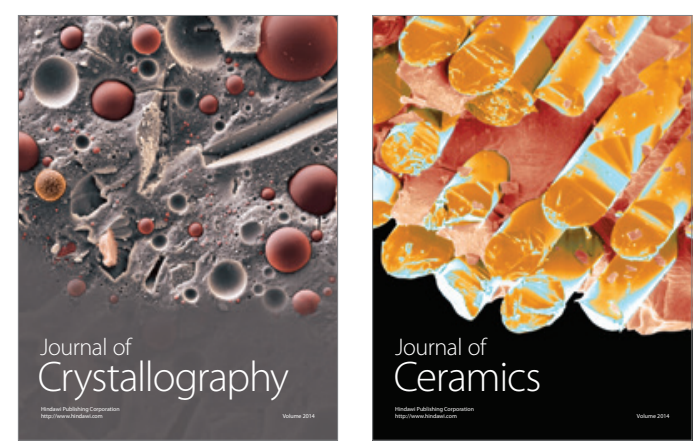
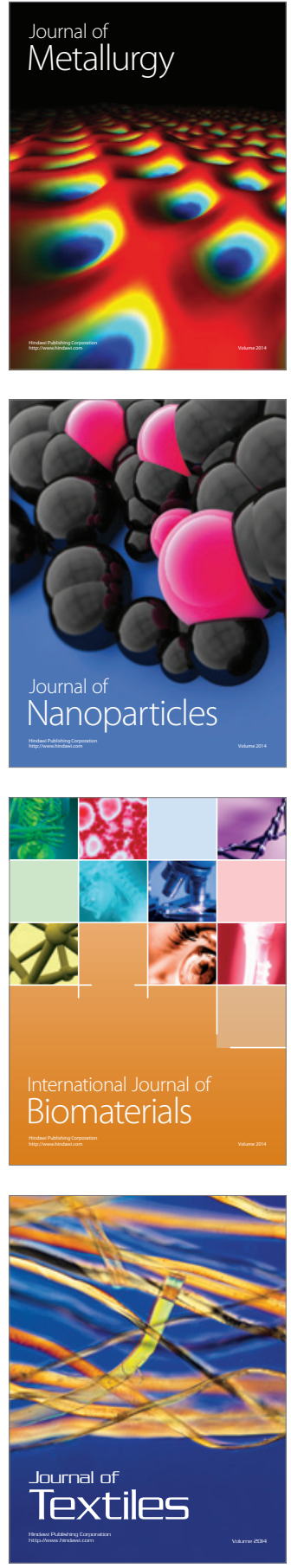